\title{
Behavioral Disorders and Drug Therapy
}

\author{
Dragana Maćešić-Petrović*, Dijana Lazic*, Mirjana Japundža-Milisavljević and \\ Aleksandra Đurić-Zdravković
}

\author{
Faculty for Special Education and Rehabilitation, University of Belgrade, Visokog Stevana 2, Belgrade, Serbia
}

\begin{abstract}
This work treats the fields of behavioral and emotional disorders such as ADHD at the children with intellectual disability in condition of possibility of applying the drug treatment. The research included the 124 examinees with mild intellectual disabilities who attend primary schools in Belgrade. The IOWA Conners scale was applied in the research for estimating the behavior and the efficiency of applied drug treatment. The research results point up the presence of behavior disturbances and disturbances of emotional functioning in a range from $11.2 \%$ to $40.4 \%$. In accordance with the gained results of research this work points out the importance of applying different method approaches such as multimodal oriented treatment based on the activities of the multidisciplinary team which includes psychopharmacological approach (sympathomimetics-psychostimulances and atoksomethyn), behavioral oriented treatment, such as psychotherapy with families and children with ADHD and social work with environment.
\end{abstract}

Keywords: Behavior, emotional disorders, intellectual disabilities, drug therapy.

\section{INTRODUCTION}

Modern theorhetical approaches about these scientific problems are based on the state that behavioral disorders are results of the disorders of the higher cortical functions (executive functions, self regulation, emotional stress and motivation). These theories allso proposed the etiological hypothesis based on the assumption about the possible couses such as methabolic dysfunction and dysfunction of neurotransmiters of catheholamine in prefrontal cortex and it`s relationship with subcortical structures (basal ganglia). The latest date in recent scientific studies reported from World Federation of ADHD point up the biological bases and multiple genetic factors such as differences in brain structures and functions as well as changes in neurotransmitter functioning within the basal ganglia and thalamocortical neurostructures.

Clinical work in diferentialy diagnostic approach are based on the possibillity to diferentiate the sympthoms of ADHD from other similar disorders or sympthoms which are in relationship with quallity and level of intellectual functioning. From this point of view, these disorders may be present in intellectual disabillity with different etiology and different degree of complexity with varios of symthoms such as:

- Hyperkinetic behavior

- $\quad$ Diferent degree of complexity of present sympthoms in various percentage in population of children with intellectual disability [1-3].

Children with the level of intellectual functioning aproximately about the IQ 50 may manifested problems of

*Address correspondence to these authors at the Faculty for Special Education and Rehabilitation, University of Belgrade,Visokog Stevana 2, Belgrade, Serbia, Tel: + 381112183 036; Fax: + 381112183 081;

E-mails: macesicd@yahoo.com,drdijanalazic@sezampro.rs attention deficit disorders and hyperactivity often in relation with stereotipical behavior. Becouse of that, some classification systhems (ICD 10) propose the category such as Hypercinetic disorders assocciate with mental retardation (or intellectual disability by the new terminology) and stereotipical movements as separate category in relation with Pervasive Developmental Disorders.

According to the World Federation of ADHD these disorders affects about $5 \%$ of the children worldwide. Recent research reports that about 5 to $12 \%$ of the children manifested these type of disorders. Disorder has onset in early childhood with long lasting period throw the childhood and has variation in degree and expression of the some of the manifested sympthoms. Becouse of this, many scientific theories are based on the statement that this is a chronical disorder (ICD -X).

Becouse of expansion of these disorders, chronical course throw the childhood and it's influence on the quallity of life it is very important for early and adequate therapeutical approach and treatment to detect these sympthoms earlier in childhood. But, what is an adequate treatment for ADHD and behavioral disorders at this point of view and at this level of scientific knowledge ? The answer is - specifically individually defined treatment program and modern theory of treatment of the behavior disorders and ADHD and it's possible related symptoms, which are based on the activities such as:

- Pharmacotherapy

- Behavior therapy

- Combination of Pharmacotherapy and behavior therapy

- $\quad$ Education of the many persons involved in activities with children such as parents, teachers and children about the ADHD and its related symptoms. 
Throw this theoretical and empirical frame of work we have observed our reserach project based on the possibillity of implementation the multimodal oriented approach to the behavior disorders and ADHD in children with intellectual disabilities.

The subject of this research was treated through the concept of social-emotional functioning of the children with mild intellectual disability, who are included in educational treatment which is standard for our environment. The article in this part of research treats two important developmentally neuropsychological aspects of behavior - attention and social-emotional functioning in the conditions of standard school treatment in which the tested children are included $[2,3]$.

These means that the behavior segments which were examined included the area such as behavior in the classroom, interaction with peers as well as the attitude towards the authority [4]. Viewed in this way, the behavior segments tested in this research, are important determinants of socio-emotional functioning of children with mild intellectual disability $[5,6]$.

With the previously defined meaningful focuses of this article, the research problem of this descriptive study includes the dilemma comprised in the question: How does the quality of social-emotional functioning, and the relationship between the attention, behavior and conceptual functioning are manifested at the children with intellectual disabilities included in the standard rehabilitation treatment?

In this way defined research problem includes the intention of viewing the quality of social and emotional functioning of the children with intellectual disabilities who are developing in the conditions of our environment and school treatment typical for the urban region of capital city Belgrade (Serbia). This may be important for the conclusions important for the other possible similar regions. This kind of conclusions make the possibility to point out the determinants of making contemporary necessary forms of multimodal oriented treatment in the conditions of education and rehabilitation of these children [4, 7-10].

The work as a part of our research project also includes the intention of highlighting the quality of mental health of the examined population of children, as an important indicator of understanding the nature of intellectual disability and its attitude towards the possible forms and ways of school treatment in which problem of mental health of this population of children should be treated and be founded which we have mentioned in our earlier published articles in this scientific area [2].

The basic aspects of this kind of work are focused towards the so-called "Dual Diagnosis" theories, in fact, theories of the dual diagnosis and the contemporary conceptual attitudes of the researches focused on the research attitude of intellectual disabilities and mental illnesses, as well as the researches which have prominent achievements in this research field [1, 11-19].

The descriptive analysis of the results gained by the research point out the direction of understanding both the nature of developmental disabilities, mental health and ADHD of the children with intellectual disabilities. It also point up the problem aspects of possible treatment of these persons with which the practical value of this work is determined.

\section{THE SAMPLE}

The sample was formed of 124 examinees of both gender distribution, from primary schools of first, second, third and fourth grade for children with mild intellectual disabilities in Belgrade, Serbia. There are 31 examinees from every class who were included in this research. The IQ in this sample is about 51 to 70, estimated by WISC scale of intellectual abilities. The chronological distribution of the examinees in the sample is in the range from 8 to 13 years.

We also tested all variables in relation with the tested sample, which can be relevant for the results of research such as:

- $\quad$ Level of intellectual functioning (IQ)

- Gender distribution

- School level

- $\quad$ Socio-economical level

- Chronological distribution

- $\quad$ Presence or absence of bilingualism, etc.

Since they are the part of our recent published wider projects, these results of the tested sample will not be present in this study [12].

\section{METHOD}

The estimation of behavior was done by the IOWA Conners scale of estimation [14]. This is well checked and standardized measuring instrument for estimation of behavior associate with ADHD. It contents the scale for parents and scale for teachers. In this research we implemented the scale for teachers. When the purpose is estimation of efficiency of medication therapy the instrument is implemented one times per week. IOWA Conners Scale is four degree scale, well chosen for assessment and research of efficiency of medication but also good choice for everyday practical evaluation of other possible models of treatment and its influence on the behavior of the tested sample. This instrument is constructed of two subscales which assess:

\section{- $\quad$ Attention deficits and motor activity}

- $\quad$ Rebellious and disobedient (undutiful, undisciplined) quality of behavior.

Maximum of completed score is 15 and that is indicator of strong and high potentially risk of behavior problems and ADHD related symptoms. Summary of all obtained scores of implemented scales is important for statistical analysis same as the independed scores achieved at the different subscales. This can be important for item analysis of estimated behavior of the tested sample which have we done in our research. This instrument is very useful in purpose of monitoring the treatment much more than for diagnostically use but it can be good choice also for both possible purposes in clinical and epidemiological studies [14].

Statistical method include descriptive statistical parameters for presentation the results of research in frequencies and percentage. Statistical analysis includes 
implementation of Person's " $r$ " coefficient of correlation in function of determining the statistical significance of the tested relationship between the implemented treatment and tested variables such as behavior, attention and conceptual disabilities of the children with intellectual disabilities.

\section{RESULTS}

The great differences according to the examined aspects of social-emotional functioning of children in our sample point out the possible conclusion about the existence of developmental disharmony. This result in special education and rehabilitation also as in the field of child psychiatry presents an important fact about the possible presence the mental health problems and problems so cooled as "dual diagnosis". These results can be suspect for the presence of the possible emotional and psychiatric disorders in tested sample.

The item - analysis implemented in this research point out the possibility to conclude about the quality of estimated behavior of the tested children in the sample.

Item-analysis of the applied scale of all the types of the examined behavior were distributed in three groups according to the percentage of representation and the level of expressed disturbances which pointed to presence of behavior disturbances. The behavior which is characterized by peevishness, destruction and proneness to quarrels, lies, and impetuous behavior were classified in the $\mathrm{C}$ group, as a group which characterizes the lowest grade of expressed disturbance.

In this group the given behavior of examinees in $74,2 \%$ cases was marked by mark "_" which points to absence of this type of behavior while $0,4 \%-18,3 \%$ of examinees had these types of behavior of different level.

Quarrelsomeness, absence of feeling for fair-play, impudence, arrogance, inclination to day-dreaming with submissiveness, and excessive activity, are the types of behavior which are the features of the B group as a group of behavior disturbance of the middle grade of expressiveness. In this group the percentage of examinees lowers to $(62,5 \%)$ while the number of children who have this type of behavior rises $(5,4 \%-19,6 \%$ depending on the force of the expressed symptom).

The behavior disturbances which appear in the examined sample with the greatest frequency include behavior like inclination to restlessness and disturbing other children by shouting, then impulsiveness, irritability and not paying attention with teasing other children and stubbornness. These types of behavior are absent in 54, $6 \%$ of sample, and their presence is in disturbances of mild level at $16,7 \%$ children. The high and strong presence of the behavior problems is present at $7,9 \%$ of the examined sample.
There is a high statistical significance of relationship between the implemented treatment and tested variables such as voluntary attention processes, quality of behavior and conceptual reasoning of the tested children which is present in Table $\mathbf{1}$.

\section{DISCUSSION}

The behavior in the standard school settings in our country (Serbia, Belgrade) of the hyperactive examinees is characterized by the expressive motor restlessness, shouting, thwarting other children during the class and by irritation and impulsiveness. Taking part in the group is characterized by teasing other children and disturbing their group and individual activities in the range up to $40 \%$ of the tested sample, which has been shown in our recent research in this area $[2,3]$.

The behavior quality, examined in this research, was directed to the analysis of emotional and social functioning of children with intellectual disability in standard treatment conditions at school settings in our region (Serbia, Belgrade). This level and quallity of social functioning was observed through the behavior of children in the classroom and cooperation with peers and teachers. The results gained by behavior estimation are distributed in two categories. These categories include behavior disturbances and attention disturbances with or without hyperactivity (graph number 1 $\& 2$ ). This distribution of the estimated behavior was done in accordance with DSM-IV classification and classification of mental and behavioral disorders of the World Health Organisation which determined the nature of quallitative interpretation of the obtained results [1,15].

The behavior estimation observed through behavior in the classroom and attitude towards authority, points to the fact that behavior disturbances appear in $11,2 \%$ of the examined sample while the harmonious behavior appears in $83,1 \%$ of the examined children. The disturbences noticed in $11,2 \%$ of examinees in classroom quarrelsomeness, irritability, explosive and unpredictable behavior which had the features of lies and stealings. The attitudes towards authority usually start from obedience and excessive need for attention of a teacher and the activity to please the teacher until impudence, arrogance, stubborness and impossible cooperation with other children in the group.

This practically points that taking children away from the family situation and parents as identification models, with discovery of their independancy through the education treatment of the child with intellectual disabilities leaves the known models of identification and has difficulties in revealing new models which would be given by teachers. They are able to notice various forms of relationships among people that they can not center to identification model. They

Table 1. Results of the Statistical Analyses of the Correlation Between the Applied Treatments and Examined Behavioral and Cognitive Functions

\begin{tabular}{|c|c|c|c|}
\hline & Attention & Conceptual functions & Behavior \\
\hline \hline Implemented & $\mathrm{r}=0.623$ & $\mathrm{r}=0.599$ & $\mathrm{r}=0.355$ \\
treatment & $\mathrm{p}<0.01$ & $\mathrm{p}<0.01$ & $\mathrm{p}<0.01$ \\
\hline
\end{tabular}




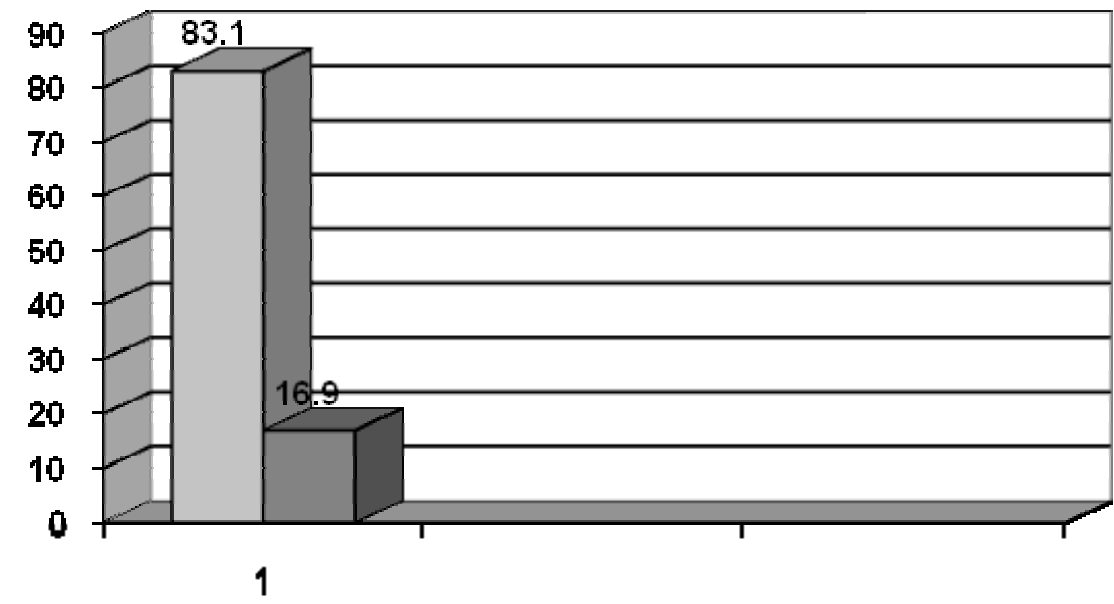

\section{DWthout disabilies}

\section{口Developmental} Disabillity

Fig. (1). Results of behavior estimation in the examined sample.

notice, but identify harder with the noticed model $[4,6,10,18]$.

The behavior disturbances with attention disturebances in educational conditions and school situations are encountered with frequency of $16,9 \%$ while the harmonious behavior and attention functioning noticed in $83,1 \%$ of children of our sample (Fig. 1). Behavior disturbances, estimeted in this part of resarch were observed through quality of behaviour and attention in the classroom and taking part in a group and group activities.

These disturbances were noticed at $16,9 \%$ of examinees and their features are lack of attention and passiveness, as the Fig. (1) has shown. They usually manifest by low level of movement coordination, lack of attention and short term attention and with the lack of possibility to finish the already started activities and proneness to daydreaming. Characteristics of taking part in group activities are proneness to mild suggestibility by other children when there is no capability to lead the group.

Observing the examined behavior characteristics with respect to the school age (grade), which points to the level of a child's personality maturity, we make a conclusion that with the growth of the education level, the number of examinees with disturbances of attention and behavior decreases, while the number of examinees with harmonious behavior rises. This points to the fact that with the older school age comes the increase of quality of attention and behavior development which is one of the conditions of more successful knowledge achievement for these children.

The disturbances of behavior with hyperactivity are frequently met in children of our sample $(7.9 \%-20.8 \%)$ while the harmonious behavior without hyperactivity is present in more than half of examinees $(54,6 \%)$. The classroom behavior of hyperactive children is expressive motor restlessness, noise and disturbing other children during the lesson and irritability and impulsiveness.Other problems are present in range from $0.4 \%-18.3 \%$ in $\mathrm{C}$ group of the presented results and in the $\mathrm{B}$ group in the range from $5.4 \%-19.6 \%$ (Fig. 2) Taking part in a group is determined by teasing other children and disturbing their individual or group activities.

Comparative analysis of the research results point out the great differences in the level and quality of the examined behavior aspects of development. Great differences in quality of the examined segments of attention and behavior development point up the presence of developmental dysharrmonia in children of our sample.

The concept of harmonious and disharmonious development is important in special education and rehabilitation from the aspect of possible appearance of psychiatric disoredrs in this population of children. The specific course of development, determined by lack of harmony among certain segments of personality, is emphasised as a risk factor in development dinamic approach to problems of duall diagnosis. According to this concept, the lack of harmony in development among certain segments of personality determines interaction of a child and environment as conflict. Conflict communication and interaction results in forming of frustrating experiences of a child which may be the base of psychopatologi qualities of a personality [3,5,7-9].

The other researchers in this field also point the importance of cognitive development problems as factors around wich psychiatric risk status of persons with intellectual disabilities are focused. Factors of cognitive development, among wich speech has an important place, are important in forming psychopathology and symptomatology in which the disorders egzists $[1,11-15,19]$.

The presence of developmental dysharmonia in children with intellectual disabilltiy, is emphasized in our earlier 

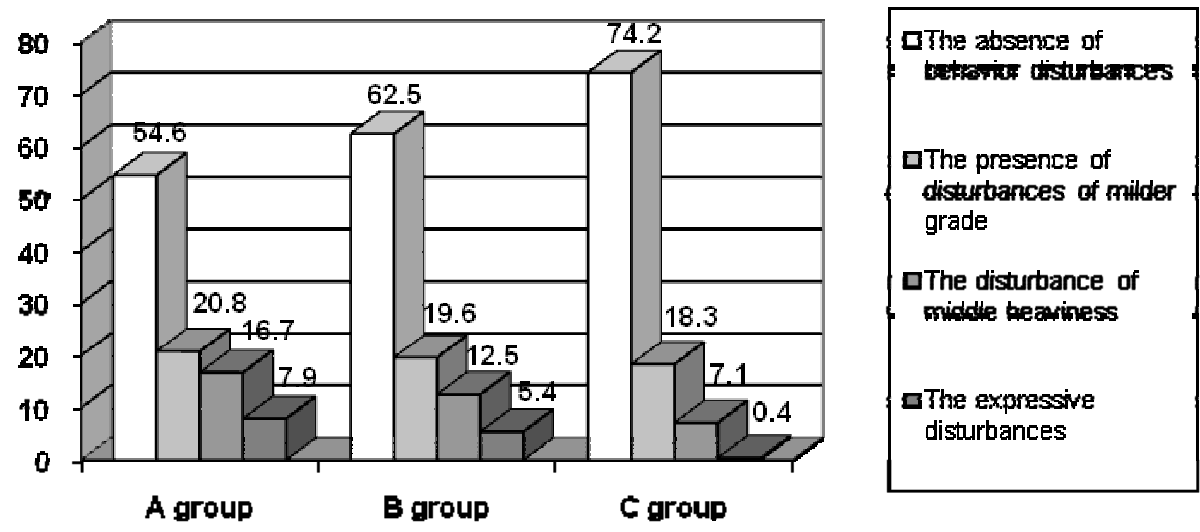

Fig. (2). The Results of the quality of Behavior of the tested sample.

research, one is of possible difficult factors of successful education and rehabilitation of these children. That is why we can conclude that a harmonious and balanced development of a child with intellectual disabillity is a central concept of contemporary diagnostics, education and rehabilitation in the field of intellectual disabilities reseraches.

The results of statistical analyssys point up the high statistical significance of the relationship between the implemented treatment, which incorporate only the parts of multimodal oriented approach, and tested behavior categories such as attention and behavior problems in concjuction with conceptual functioning problems of the tested sample. This point up the conclusion about he necessity of implementation the whole multimodal oriented approach to attention deficits and behavioral problems of the children with intellectual disabilities. These includes:

- $\quad$ Team work of proffessionals and non- professionals (child psychiatrists, special educators, teachers, parents)

- Multimodal treatment which means strategy of combination of therapeutical approach to ADHD at children with or without intellectual disabilities

- Complementary tretament (education, psychosocial intervention, combination of special education methods such as reeducation of psychomotor activity etc.)

- Psychopharmacotherapy for cases for whom it is necesary

- Individual educational programs (IEP)

- Individual treatment programs (ITP).

Adaptation of the treatment must be focused to the developmental abilities of the child.

\section{CONCLUSION REMARKS}

According to the given aims od this descriptive study we can conclude that the problems of social emotional functioning of the examined sample children appear with frequency about the $40.4 \%$ depending on the examined field of behavior. This points out the neccessity in implementation the more various method approaches to education and treatment of children with developmental and intellectual disability.

In this part of research we point up the therapeutically approach which performs role of special educator in the multidisciplinary team oriented to multimodal approach to treatment of ADHD. In our earlier articles we proposed the implementation of method of treatment of reeducation of psychomotor activity in children with behavioral disorders and hyperactivity, which have been established at the Institute of Mental Health in Belgrade following the methodological concept of French authors and adjusted to the population of our environmental milieu, with the possibility of implementation and adaptation in cases of ADHD or behavior and attention disorders in other milieus, as well [2,3]. Modern approach is based at the multimodal oriented treatment based on the activities of the multidisciplinary team and includes psychopharmacological approach (sympathomimetics-psychostimulances and atoksomethyn), behavioral oriented treatment, such as psychotherapy with families and children with or without intellectual disabilities in combination with ADHD and social work with environment.

\section{REFERENCES}

[1] American Psychiatric Association. Diagnostic and statistical manual of mental disorders: DSM-IV-TR.; Washington, DC American Psychiatric Association: Washington, 2000.

[2] American Psychiatric Association. Diagnostic and statistical manual of mental disorders $4^{\text {th }}$ ed. American Psychiatric Association: Washington, 1994.

[3] Beier, C.D. In Mental Retardation; Kirk, A.S.; Heber, R.; Ed. The University of Chicago Press: Chicago, 1972; pp.77-108.

[4] Broman, H.S.; Grafman, J. A typical cognitive deficits in developmental disorders - implication for brain function; LEA Publ.: London, 1994.

[5] Craig, W. Childhood social development; Blackwell publishing: London, 2000.

[6] Došen, A. Psychiatric and behavior disorders among mentally retarded adults. Došen, A, Ed.; New Oxford Textbook of Psychiatry, Oxford University Press: New York, 2000.

[7] Došen, A.; Kenneth, D. In Children and adults with mental retardation; Došen, A.; Kenneth, D., Ed.; American Psychiatric Press, Inc.: Arlington, 2001; pp. 519-28.

[8] Došen, A.; Van, G.; Zwanikken, G. J. Development dynamic relationship therapy, treatment of mental illness and behavioral disorder in the mentally retarded. Proceedings of the International Congress, May, $3^{\text {rd }} \& 4^{\text {th }}$, Logon Publications: Amsterdam, 1990, pp. 45-70.

[9] Falissard, B.; Ralston, S. J. An overview of attention deficit hyperactivity disorder observational research in europe, european 
society for child and adolescent psychiatry (ESCAP), September/October, Paris, 2003; pp. 23.

[10] Granger, A.D.; Kivlighan, K.T. Integrating biological, behavioral and social levels of analysis in early child development: progress, problems and prospects. Chil. Dev., 2003, 74 (4), 1058-64.

[11] Japundza - Milisavljević, M.; Maćešić- Petrović, D. Executive functions in children with intellectual disabilities. Br J. Dev. Dis., 2008, 54 (2) No.107, pp.113-21.

[12] Macesic-Petrovic, D.; Japundza-Milisavljevic M.; DjuricZdravkovic A.: Intellectual functioning and behavioral disorders, Altern. Defic. Hyperact. Disord., 2009, 1 (1), 25-31.

[13] Maćešić-Petrović, D.; Žigić, V. Laka intelektualna ometenostrazvojne $i$ funkcionalne specifičnosti; Fakultet za specijalnu edukaciju i rehabilitaciju i CIDD: Beograd, 2009.

[14] Pelham, W.E.JR.; Milich, R.; Murphy, D.; Murphy, H.A. IOWA Conners Rating Scale. Avaliable from AM Chronis - www.ingentaconnect.com/content/proedcw/jebd/2002/00000009/0 0000004/art00001?crawler=true [Accessed 2001, 1989].

[15] Robinson, G.E.; Ben-Shahar, Y. Social behavior and comparative genomics: new genes or new gene regulations? Genes. Brain. Behav., 2002, 1 (4), 197-204

[16] Sciacca, K.; Hatfield, A.B. The family and the dually diagnosed patient; double jeopardy chronic mental illness and substance disorders, Harwood Academic Publishers: Switzerland, 1995, Chap 12, pp. 193-209.

[17] Sciacca, K.; Thompson, M.C. Program development and integrated treatment across systems for dual diagnosis: mental illness, drug addiction and alcoholism. J. Men. Adm., 1996, 23 (3),pp. 288-97.

[18] Szymanski, S.L.; Crocker, C.A. In Comprehensive handbook of psychiatry; Freedman, A.; Kaplan, H.; Saddock, B., Ed.; Williams and Wilkins: Baltimore, 1985; pp.420-31.

[19] World Health Organisation. ICD-10, ZUNS: Belgrade, 1992.

(C) Maćešić-Petrović et al.; Licensee Bentham Open.

This is an open access article licensed under the terms of the Creative Commons Attribution Non-Commercial License (http://creativecommons.org/licenses/by-nc/3.0/) which permits unrestricted, non-commercial use, distribution and reproduction in any medium, provided the work is properly cited. 